\title{
Predicting the Consumer Acceptability of Dried MD2 and Smooth Cayenne Pineapple Pulps from Chemical Composition
}

\author{
Francis Appiah (Corresponding author), Patrick Kumah \& David Oppong \\ Department of Horticulture, Faculty of Agriculture, CANR \\ Kwame Nkrumah University of Science and Technology, Kumasi, Ghana \\ Tel: 233-242-070-556 E-mail: fappiah_sp@yahoo.com
}

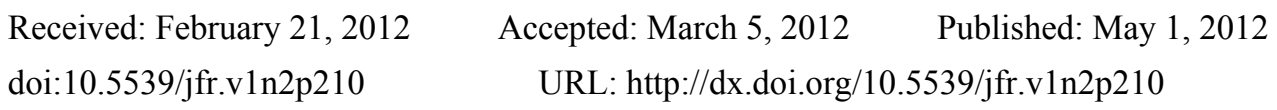

\begin{abstract}
Drying of pineapple (Ananas comosus) pulp enhances shelf life while assuring all-year-round availability of pineapple in different forms. The difficulty in selecting suitable fruit pulps for producing acceptable dried pulp needs to be addressed in order to reduce variability in dried pineapple pulps and predict consumer acceptability. MD2 and Smooth cayenne fruits were used for the study. Relationships existing between chemical and sensory characteristics of oven-dried pineapple pulps were determined using standard procedures. While a strong positive correlation was found between total soluble solids (TSS) and taste (SC=0.98; MD2=0.99) a negative association was found between TSS and crispness $(\mathrm{SC}=-0.98$; $\mathrm{MD} 2=-0.99)$ as well as between total titratable acidity (TTA) and taste $(\mathrm{SC}=-0.99$; $\mathrm{MD} 2=-0.98)$. The study showed that TSS of the fresh fruit was the single most important predictor of overall acceptability of dehydrated pulps. TSS of fresh fruits could therefore be used to select fresh pulps for dehydration.
\end{abstract}

Keywords: Pineapple, Dehydration, Sensory evaluation, Smooth Cayenne, MD2

\section{Introduction}

Pineapple (Ananas comosus), is a member of the family Bromeliaceae. It is a good source of ascorbic acid (vitamin C), vitamin A, calcium, phosphorus, iron, potassium and thiamine (USDA, 2005). They are eaten as dessert fruits throughout the tropical and sub tropical areas of the world (Francis, 1982). Thailand, Philippines, Brazil and China are the main producers in the world supplying nearly $50 \%$ of the total world output (Athey, 1995). Other important producers include India, Nigeria, Kenya, Indonesia, México and Costa Rica. According to Francis (1982), nearly $70 \%$ of the pineapple is consumed as fresh. The problem with fresh pineapple is how best the fruits can be stored at room temperature in order to minimize postharvest losses. This has resulted in the adoption of various processing techniques in extending the shelf life of the fresh fruits so as to ensure all year round availability of the fruit in different forms. Among the promising technologies is drying. Drying of fruits while extending shelf life could result in products with varying quality characteristics. The high variability in the eating quality of dehydrated pineapple pulp has been attributed to the use of fruits with different chemical characteristics, such as fruits at different stages of ripening (Barrett, Somogyi \& Ramaswamy, 2005). In order to minimize the variability, ensure consumer acceptance and enhanced profitability dried pineapple fruit producers need a good criteria for selecting fresh fruits that would make good chips. This study therefore, sought to identify important easy-to-determine fresh pulp characteristics that could be used to predict quality and consumer acceptability dried pineapple pulps.

\section{Materials and Methods}

\subsection{Location and location of experiment}

Fully mature fresh Smooth Cayenne and MD2 fruits were harvested from Bomarts Farms Limited at Nsawam in the Eastern Region of Ghana and transported to the laboratory of the Department of Horticulture, Faculty of Agriculture, KNUST, Kumasi for analysis.

\subsection{Sample preparation}

Fresh Smooth Cayenne and MD2 pineapple at different stages of ripening (Unripe, half-ripe and fully ripe) fruits were washed, peeled and sliced into circular discs (slices) of dimension $1 \mathrm{~cm}$ thickness. The slices were then 
spread evenly on trays lined with aluminum foil. Trays were then placed in a Wagtech oven (Model GP120SSE300HYD) at temperature of $67{ }^{\circ} \mathrm{C}$ in an oven for 24 hours. The slices were periodically turned to ensure uniform drying. The dried slices were allowed to cool for about 30 minutes in a dessicator prior to analysis.

\subsection{Quality assessment}

Standard procedures were used for determination of moisture content, total titratable acidity (TTA), total soluble solids (TSS) and sensory characteristics.

\subsubsection{Moisture content}

Moisture content was determined according to the method of the AOAC (AOAC, 1990). Two (2 g) of pineapple pulp was placed in a crucible and dried in an oven for 24 hours at $60^{\circ} \mathrm{C}$. Moisture content was estimated using the formula: (Initial wt-dry wt/initial wt) $\times 100$.

\subsubsection{Total soluble solids (TSS)}

The total soluble solids content was measured using a Lafayette hand refractometer. A $30 \mathrm{~g}$ of the pulp tissue in $90 \mathrm{ml}$ of distilled water was blended with a laboratory blender for 2 minutes and filtered. A single drop of the filtrate was placed on the prism of the refractometer. The percentage total soluble solid was read by pointing the refractometer towards a light source. The recorded value was then multiplied by three since the initial pulp sample was diluted three times with distilled water (Dadzie \& Orchard, 1997).

\subsubsection{Total titratable acidity (TTA)}

Thirty grams (30g) of the pulp was weighed into a blender plus $90 \mathrm{ml}$ distilled water, blended for two minutes and filtered. $25 \mathrm{ml}$ of the filtrate was transferred into a $125 \mathrm{ml}$ conical flask. Another $25 \mathrm{ml}$ distilled water and four to five drops of phenolphthalein indicator were added. This solution was titrated against $0.1 \mathrm{~N}$ sodium hydroxide until there was a sharp colour change from light yellow to pink. The titre volume of $\mathrm{NaOH}$ added was multiplied by the citric acid factor (0.07) to obtain the total titratable acidity (Dadzie \& Orchard, 1997).

\subsubsection{Sensory evaluation}

Sensory evaluation was carried out on the chips using 30 untrained panelists. Sensory attributes assessed were appearance, taste, aroma, crispness, mouth feel and overall acceptability. A hedonic scale of 1-5 (1 - Dislike very much; 2 - Dislike slightly; 3 - Neither like nor dislike; 4 - Like slightly; 5 - Like very much) was used for the assessment.

\subsection{Statistical analyses}

Analysis of variance was carried out on collected triplicate data using GENSTAT (Discovery edition 3). Least significant difference (Lsd) test was used to determine differences between means.

\section{Results and Discussion}

\subsection{Chemical composition of fresh pineapple fruits used to produce dried pineapple pulp}

\subsubsection{Moisture Content}

During ripening the moisture content of Smooth Cayenne increased from $684.0 \mathrm{~g} \mathrm{~kg}^{-1}$ in unripe to $693.0 \mathrm{~g} \mathrm{~kg}^{-1}$ in full ripe representing a $1.3 \%$ increase with ripening (Table 1). On the other hand, MD2 increased from $798.0 \mathrm{~g}$ $\mathrm{kg}^{-1}$ in unripe to $812.0 \mathrm{~g} \mathrm{~kg}^{-1}$ in full ripe, representing an increase of $1.8 \%$ in the moisture of the fruits. This gradual increase in moisture content of the pineapple pulps during ripening could be attributed to loss of moisture from the peels to the pulp (Kays, 1991). The increase in moisture during ripening allows fruit solutes, usually sugars, to dissolve inducing sweetness.

(Table 1)

\subsubsection{Changes in total soluble solids (TSS) Content}

There was a general increase in total soluble solids in both varieties during ripening. Whereas TSS increased from $97.0 \mathrm{~g} \mathrm{~kg}^{-1}$ to $114.0 \mathrm{~g} \mathrm{~kg}^{-1}$ in Smooth Cayenne, MD2 increased from $117.0 \mathrm{~g} \mathrm{~kg}^{-1}$ to $126.0 \mathrm{~g} \mathrm{~kg}^{-1}$ representing increases of $17.5 \%$ and $7.7 \%$ respectively. Increase in TSS during ripening is a result of the transformation of fruit starch into soluble sugars under the action of the phosphorylase enzyme (Nakasone and Paull, 1998). The observed increase in sweetness during ripening could probably be attributed to increased levels of sucrose, glucose and fructose which are known to be responsible for sweetness in pineapple (Bates, Morris \& Crandall, 2001).

(Table 2) 


\subsubsection{Changes in total titratable acid (TTA) content}

The total soluble solids content of MD2 $\left(1.8 \mathrm{~g} \mathrm{~kg}^{-1}\right)$ was significantly lower than Smooth Cayenne $\left(4.5 \mathrm{~g} \mathrm{~kg}^{-1}\right)$. The total titratable acidity for Smooth Cayenne decreased from $\left(4.9 \mathrm{~g} \mathrm{~kg}^{-1}\right)$ in unripe to $\left(4.1 \mathrm{~g} \mathrm{~kg}^{-1}\right)$ in full ripe whiles that of MD2 decreased from $\left(2.5 \mathrm{~g} \mathrm{~kg}^{-1}\right)$ in unripe to $\left(1.4 \mathrm{~g} \mathrm{~kg}^{-1}\right)$ in full ripe. The two major organic acids in pineapple are citric and malic acids (Saradhuldhat \& Paull, 2007). During ripening the acids are involved in protein synthesis resulting in the observed decrease in total titratable acidity (Lacey, Hancock \& Ramsey, 2009).

(Table 3)

\subsubsection{Changes in sugar: acid ratio}

The sugar:acid ratio of the of both Smooth Cayenne and MD2 fruit pulps increased as ripening advanced. While for Smooth Cayenne the ratio increased from 19.8:1 to 27.8:1, MD2 increased from 46.8:1 to 90.0:1 with ripening (Table 4). During ripening fruit acids are degraded, the sugar content increases and the sugar:acid ratio increases (Shashirekha \& Patwardhan, 1976) as was observed in this study. Sugar-acid ratio has been reported to contribute to the unique flavor of fruits (Colaric, Veberic, Stamjoar \& Hudina, 2005). It is an indicator of commercial and organoleptic ripeness. Overripe fruits have very low levels of fruit acid and therefore lack characteristic flavor (OECD, 2011). The higher levels of sugar:acid ratio in MD2 probably contributed to MD2 having superior taste.

(Table 4)

\subsection{Sensory evaluation}

\subsubsection{Taste}

The characteristic taste of fruits is determined by the content of sugars and organic acids (Kader, 2008). According to the sensory panel, the taste of dehydrated MD2 pulp was significantly more acceptable than Smooth Cayenne irrespective of the stage of ripening (Table 5). Generally, the unripe dehydrated pulps were the least accepted among the 2 varieties. The full ripe pulps were the most agreeable to the sensory that scored them 4.9 and 4.5 for MD2 and Smooth Cayenne respectively. Whereas the differences between half-ripe and full ripe were significant for Smooth Cayenne, MD2 did not show any significant difference. This means that half-ripe MD2 could be used to produce chip without adverse effect on taste. The strong positive correlation between TSS and taste (MD2, r=0.98; Smooth Cayenne, $\mathrm{r}=0.99$ ) as well as the strong negative correlation (MD2, $\mathrm{r}=-0.99$; Smooth Cayenne, $\mathrm{r}=-0.98$ ) between taste and TTA suggest that the taste of dehydrated MD2 and Smooth Cayenne pineapple pulps are influenced by TSS and TTA.

(Table 5)

\subsubsection{Appearance}

Appearance is one of the most important factor consumers take into consideration in purchasing a product. Dried pulp produced with Half ripe and full ripe fruits from both MD2 and Smooth Cayenne were perceived by the sensory panel to be similar in terms of their appearance. However, the differences between unripe and half ripe or fully ripe MD2 were found to be significant. According to Bartolome, Ruperez \& Fuster (1996) the development of carotenoids provide ripe pineapples with an attractive colour. This probably contributed to the more acceptable appearance of the dehydrated pulp produced using fully ripe pulp. The results suggest that both Smooth Cayenne and MD2 could perform similarity in terms of the appearance of their pulps when their half ripe and fully ripe pulps are dehydrated.

\section{(Table 6)}

\subsubsection{Aroma}

Aroma is produced by the volatile synthesized during fruit ripening and may include aldehydes, alcohols, esters, lactones, terpenes and sulfur compounds (Kader, 2008). Volatiles responsible for aroma originate from proteins, carbohydrates, lipids and vitamins. Generally, the unripe pulps, irrespective of the variety were statistically lower than half ripe and full ripe which were judged to be similar. The aroma of MD2 (4.1) was reported to be statistically similar to Smooth Cayenne (3.8) as indicated in Table 7. In the study, it was observed that the full ripe dehydrated pulps were more accepted than the half-ripe and unripe, variety notwithstanding.

(Table 7) 


\subsubsection{Crispness}

The crispness of the dried pulp from the unripe was most preferred to that of the half ripe and full ripe. The crispness of chips from full ripe pineapples were the least preferred with a mean sensory score of (2.5) in Smooth Cayenne and (1.5) in MD2 (Table 8). This implies that the crispness of Smooth Cayenne was more acceptable than MD2. This could be attributed to increased sugar levels thereby making the chips gummy instead of crispy in the case of MD2 variety (Food Resource, 2009; Kitts, 2011).

(Table 8)

\subsubsection{Mouthfeel}

Mouth feel gives an indication of the mouth sensation the chips give in the mouth. Table 9 shows the scoring for mouthfeel of dehydrated pineapple slices. There were statistical differences between the mouthfeel scores of unripe (3.7) and full ripe (4.5) Smooth Cayenne. On the other hand, there were differences between unripe MD2 (3.5) and half ripe (4.6) and full ripe (4.5) pulps as shown in Table 8. According to the sensory panel the mouth-feel of pulps at different stages of ripening were significantly different. The unripe stages were less acceptable than both half-ripe and ripe. The implication of this finding is that both half-ripe and fully ripe fruits of Smooth cayenne and MD2 could be used to produce dehydrated pulp of acceptably similar mouthfeel.

\section{(Table 9)}

\subsubsection{Overall acceptability}

While both unripe Smooth Cayenne and MD2 were generally, neither liked nor disliked, all their half ripe and full ripe dehydrated pulps were scored acceptable to the sensory panel. As regards the full ripe pulps, Smooth Cayenne was preferred. However, the most acceptable dehydrated pulp was produced by MD2 at the half ripe (4.7) as indicated in Table 10. The results of this study has shown that Smooth Cayenne (4.0) and MD2 (3.8) produced equally acceptable dehydrated pulp.

(Table 10)

\subsection{Empirical relationships between chemical attributes and overall acceptability}

There were strong positive correlations between taste and total soluble solids for Smooth Cayenne $(\mathrm{r}=0.98)$ and MD2 ( $r=0.99)$. However, the correlation between total titratable acidity and taste was an inverse one for both Smooth Cayenne ( $\mathrm{r}=-0.99)$ and MD2 (0.98; Table 11). The results indicate that as TSS (sweetness) increases and TTA (acidity) decreases, the taste of the dried pulp improved (Kader, 2008). This explains why the dried pulp produced using ripe fruits was preferred to the unripe.

(Table 12)

Regression equations (Table 12) from the study suggested that the TSS content of the fresh pineapple fruits was important in explaining the variability in crispness $\left(\mathrm{R}^{2}=0.82\right)$, taste $\left(\mathrm{R}^{2}=0.78\right)$ and aroma $\left(\mathrm{R}^{2}=0.62\right)$ of the dried pulp. Whereas aroma and taste of the dried pulp improved with increasing TSS content of the fresh fruit pulp, crispness was adversely affected. On the other hand, mouthfeel of the dried pulp which was found to be a determinant of overall acceptability $\left(\mathrm{R}^{2}=0.80\right)$, was itself determined by taste $\left(\mathrm{R}^{2}=0.75\right)$ and crispness $\left(\mathrm{R}^{2}=0.64\right)$; which has been shown to be influenced by TSS content of the fresh pineapple fruit in this study. TSS of the fresh pineapple fruit pulp could therefore be used to predict the acceptability of sensory attributes of dehydrated pineapple pulp.

\section{Conclusion}

The most acceptable stage of ripening for MD2 for the production of dehydrated pulp was the 'half ripe stage'. On the other hand, Smooth Cayenne produced its best dehydrated pulp from the full ripe stage. Total Soluble Solids content of the pineapple fruits found to be the single most important predictor of the acceptability of the dried pulps. Producers of dried pineapple pulp could therefore predict the acceptability of their dried pulps by assessing the total soluble solid content of the fresh fruits.

\section{References}

AOAC. (1990). Official methods of analysis of the Association of Official Analytical Chemists, $15^{\text {th }}$ ed, Washington D. C.

Arthey, D. (1995). Food Industries Manual. In: Ranken, M. D., Kill, R. C. and British Food Manufacturing Industries Research Association Eds. Fruit and Vegetable Product. London. Blackie Academic and Professional.

Barrett, D. M., Somogyi, L., \& Ramaswamy, H. S. (Eds). (2005). Processing fruits. $2^{\text {nd }}$ ed. CRC Press. London. 
Bartolome, A., Ruperez, P., \& Fuster, C. (1996). Freezing Rate and Frozen Storage Effects on Color and Sensory Characteristics of Pineapple Fruit Slices. Journal of Food Science, 61, 154-156. http://dx.doi.org/10.1111/j.1365-2621.1996.tb14747.x

Bates, R. P., Morris, J. R., \& Crandall, P. G. (2001). Principles and practices of small and medium-scale fruit processing. FAO Agricultural Services Bulletin 146. [online] Available : http://www.fao.org/docrep/005/y2515e/y2515e00.htm [March 19, 2012]

Colaric, M., Veberic, R., Stampar, F., \& Hudina, M. (2005). Evaluation of peach and nectarine fruit quality and correlation between sensory and chemical attributes. Journal of the Science of Food and Agriculture, 85, 2611-2616. http://dx.doi.org/10.1002/jsfa.2316

Dadzie, B. K., \& Orchard, J. (1997). Routine Post Harvest Screening of Banana/Plantain Hybrids: Criteria and Methods. INIBAP Technical Guidelines 2. Wageningen, The Netherlands. [online] Available: http://bananas.bioversityinternational.org/files/files/pdf/publications/tg2_en.pdf [June 14, 2011]

Food Resource. (2009). Fruits-Vegetables. Oregon state University. [online] Available: http:/foodoregonstate.edu/learn/fruitveg.html [Accessed 26 April, 2011].

Francis, F. J. (1982). Analysis of anthocyanins. In: Markakus, P (Ed), Anthocyanins as food colour. New York: Academic Press.

Kader, A. A. (2008). Perspective: Flavor quality of fruits and vegetables. Journal of the Science of Food and Agriculture, 88, 1863-1868. http://dx.doi.org/10.1002/jsfa.3293

Kays, S. J. (1991). Postharvest Physiology of Perishable Plant Products. Van Nostrand Reinhold New York.

Kitts, D. D. (2011). The functional role of sugars in food. Canadian Sugar Institute. [online] Available: http:/www.sugar.ca/English/healthprofessionals/carboIssue4.cfm. [April 26, 2011]

Lacey, K., Hancock, N., \& Ramsey, H. (2009). Measuring internal maturity of citrus. Western Australian Agriculture Authority. Farmnote no. 354. [online] Available: http://www.agric.wa.gov.au/objtwr/imported_assets/content/hort/fn/cp/citrusfruits/FN_testing_of_citrus.pdf. [April 25, 2011)

Nakasone, H. Y., \& Paull, R. E. (1998). Tropical Fruits. CAB International,198 Madison Avenue, New York, U. S. A.

OECD. (2011). Guidance on objective tests to determine quality of fruits and vegetables and dry and dried produce. Available: http://www.oecd.org/dataoecd/32/47/19515719.pdf [April 25, 2011]

Saradhuldhat, P., \& Paull, R. E. (2007). Pineapple organic acid metabolism and accumulation during fruit development. Scientia Horticulturae, 112 (3), 297-303. http://dx.doi.org/10.1016/j.scienta.2006.12.031

Shashirekha, M. S., \& Patwardhan, M. V. (1976). Changes in amino acids, sugars, and nonvolatile acids in a ripening mango fruit (Mangifera indica, 'Badami' variety). Lebensmittel-Wissenschaft \&Technologie, 9, 369-370.

USDA (2011). National nutrient database for standard release 18. (2005). Available: http://usda.gov/ fnic/ food comp/ search/ [April 26, 2011]

Table 1. Changes in moisture content of Smooth Cayenne and MD2 pineapple fruit during ripening $\left(\mathrm{g} \mathrm{kg}^{-1}\right)$

\begin{tabular}{llll}
\hline & Smooth Cayenne & MD2 & Means \\
\hline Unripe & 684.0 & 798.0 & 741.0 \\
Half ripe & 685.0 & 808.0 & 747.0 \\
Full ripe & 693.0 & 812.0 & 752.0 \\
\hline Means & 687.0 & 806.0 & \\
Lsd at 0.05 & 0.10 & & \\
\hline
\end{tabular}


Table 2. Changes in total soluble solids during ripening $\left(\mathrm{g} \mathrm{kg}^{-1}\right)$

\begin{tabular}{llll}
\hline & Smooth Cayenne & MD2 & Means \\
\hline Unripe & 97.0 & 117.0 & 107.0 \\
Half ripe & 108.0 & 122.0 & 115.0 \\
Full ripe & 114.0 & 126.0 & 120.0 \\
\hline Means & 106.0 & 121.0 & \\
Lsd at 0.05 & 1.3 & & \\
\hline
\end{tabular}

Table 3. Changes in total titratable acidity during ripening $\left(\mathrm{g} \mathrm{kg}^{-1}\right)$

\begin{tabular}{llll}
\hline & Smooth Cayenne & MD2 & Means \\
\hline Unripe & 4.9 & 2.5 & 3.7 \\
Half ripe & 4.5 & 1.9 & 3.2 \\
Full ripe & 4.1 & 1.4 & 2.7 \\
\hline Means & 4.5 & 1.8 & \\
Lsd at 0.05 & 0.01 & & \\
\hline
\end{tabular}

Table 4. Changes in Sugar:Acid Ratio in pineapple fruits during ripening

\begin{tabular}{llll}
\hline & Smooth Cayenne & MD2 & Means \\
\hline Unripe & 19.8 & 46.8 & 28.9 \\
Half ripe & 24.0 & 64.2 & 35.9 \\
Full ripe & 27.8 & 90.0 & 44.4 \\
\hline Means & 23.6 & 67.2 & \\
Lsd at 0.05 & 0.34 & & \\
\hline
\end{tabular}

Table 5. Sensory scoring for taste of chips

\begin{tabular}{llll}
\hline & Smooth Cayenne & MD2 & Means \\
\hline Unripe & 3.2 & 3.8 & 3.5 \\
Half ripe & 4.0 & 4.6 & 4.3 \\
Full ripe & 4.5 & 4.9 & 4.7 \\
\hline Means & 3.9 & 4.4 & \\
Lsd at 0.05 & 0.37 & & \\
\hline
\end{tabular}

Table 6. Sensory scoring for appearance of chips

\begin{tabular}{llll}
\hline & Smooth Cayenne & MD2 & Means \\
\hline Unripe & 3.9 & 3.9 & 3.9 \\
Half ripe & 4.1 & 4.4 & 4.2 \\
Full ripe & 4.2 & 4.1 & 4.2 \\
\hline Means & 4.0 & 4.1 & \\
Lsd at 0.05 & 0.45 & & \\
\hline
\end{tabular}

Table 7. Sensory scoring for aroma of chips

\begin{tabular}{llll}
\hline & Smooth Cayenne & MD2 & Means \\
\hline Unripe & 3.1 & 3.5 & 3.3 \\
Half ripe & 4.0 & 4.3 & 4.1 \\
Full ripe & 4.2 & 4.4 & 4.3 \\
\hline Means & 3.8 & 4.1 & \\
\hline Variety & Lsd $(\mathrm{P}=0.05)=0.45$ & & \\
Stage of ripening & Lsd $(\mathrm{P}=0.05)=0.49$ & & \\
Variety x Stage of ripening & Lsd $(\mathrm{P}=0.05)=0.70$ & &
\end{tabular}


Table 8. Sensory scoring for crispness of chips

\begin{tabular}{llll}
\hline & Smooth Cayenne & MD2 & Means \\
\hline Unripe & 4.6 & 3.5 & 4.1 \\
Half ripe & 3.5 & 2.5 & 3.0 \\
Full ripe & 2.5 & 1.5 & 2.0 \\
\hline Means & 3.5 & 2.5 & \\
\hline
\end{tabular}

$\operatorname{Lsd}(\mathrm{p}=0.05)=0.27$

Table 9. Sensory scoring for mouth-feel of chips

\begin{tabular}{llll}
\hline & Smooth Cayenne & MD2 & Means \\
\hline Unripe & 3.7 & 3.5 & 3.6 \\
Half ripe & 4.1 & 4.6 & 4.3 \\
Full ripe & 4.5 & 4.5 & 4.5 \\
\hline Means & 4.1 & 4.2 & \\
\hline
\end{tabular}

$\operatorname{Lsd}(\mathrm{p}=0.05)=0.55$

Figure 10. Sensory score for overall acceptability of chips

\begin{tabular}{llll}
\hline & Smooth Cayenne & MD2 & Means \\
\hline Unripe & 3.3 & 3.5 & 3.4 \\
Half ripe & 4.1 & 4.7 & 4.4 \\
Full ripe & 4.5 & 3.3 & 3.9 \\
\hline Means & 4.0 & 3.8 & \\
\hline
\end{tabular}

$\operatorname{Lsd}(\mathrm{p}=0.05)=0.31$

Table 11. Correlation between chemical and sensory parameters

\begin{tabular}{llllll}
\hline Variety & Parameter & Taste & Crispness & Mouthfeel & $\begin{array}{l}\text { Overall } \\
\text { Acceptability }\end{array}$ \\
\hline Smooth Cayenne & TSS & 0.98 & -0.98 & 0.97 & 0.99 \\
& TTA & -0.99 & 0.99 & -0.99 & -0.98 \\
MD2 & TSS & 0.99 & -0.99 & 0.85 & 0.97 \\
& TTA & -0.98 & 0.99 & -0.82 & -0.96
\end{tabular}

TSS - Total soluble Solids $\quad$ TTA - Total Titratable Acidity

Table 12. Empirical relationships existing between sensory and chemical properties of pineapple pulp

\begin{tabular}{llll}
\hline Equation No. & Linear Regression Equation & R2 & P-value \\
\hline 1 & Crispness $=13.7-0.09$ Total Soluble Solids & 0.82 & 0.014 \\
2 & Aroma $=-0.50+0.04$ Total Soluble Solids & 0.62 & 0.041 \\
3 & Taste $=-1.85+0.05$ Total Soluble Solids & 0.78 & 0.020 \\
4 & Mouthfeel $=1.45+0.65$ Taste & 0.75 & 0.025 \\
5 & Mouthfeel $=5.18+0.34$ Crispness & 0.64 & 0.057 \\
6 & Overall acceptability $=0.36+0.86$ Appearance & 0.92 & 0.002 \\
7 & Overall acceptability $=2.48+0.33$ Mouthfeel & 0.80 & 0.010 \\
8 & Overall acceptability $=3.07+0.19$ Taste & 0.50 & 0.020 \\
\hline
\end{tabular}

